\title{
ЯЗЫКОЗНАНИЕ
}

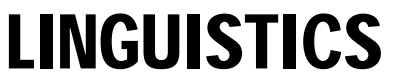

УДК 378.1

DOI 10.18413/2712-7451-2020-39-3-466-476

\section{Система вокализма национального варианта французского языка Швейцарии: оппозиции гласных звуков}

\author{
Куксова Е.Л. \\ Белгородский государственный национальный исследовательский университет, \\ Россия, 308015, г. Белгород, ул. Победы, 85 \\ E-mail: kuksova@bsu.edu.ru
}

\begin{abstract}
Аннотация. Французский язык представлен множеством вариантов за пределами метрополии, например, в Швейцарии. Несмотря на множество уникалий, нестандартное произношение в наибольшей степени противопоставляет французский язык метрополии национальному варианту французского языка Швейцарии. Ислледования, посвященные системе вокализма национального варианта французского языка Швейцарии, не отображают фонетические уникалии современной франкоговорящей Швейцарии. В связи с этим автором систематизированы данные по фонетическим явлениям французского языка Швейцарии в системе вокализма. Изучению подвергаются фонетические оппозиции $[\tilde{\varepsilon}]-[\tilde{a}],[\alpha]-[a],[0]-[o],[e]-[\varepsilon],[\tilde{\varepsilon}]-[\tilde{e}]$. В ходе работы с фактическим материалом исследования автор фиксирует наличие либо отсутствие выявленных оппозиций, а также уточняет частотность каждого случая оппозиции в целом, вне зависимости от франкоговорящего кантона.
\end{abstract}

Ключевые слова: франкофония, фонетика, вокализм, акцент, языковое варьирование, Швейцария, Франция, Западная Европа.

Для цитирования: Куксова Е.Л. 2020. Система вокализма национального варианта французского языка Швейцарии: оппозиции гласных звуков. Вопросы журналистики, педагогики, языкознания, 39 (3): 466-476. DOI 10.18413/2712-7451-2020-39-3-466-476

\section{The national french language variant's vocalism systemin switzerland: vowels'oppositions}

\author{
Elena L. Kuksova \\ Belgorod National Research University, \\ 85 Pobeda St, Belgorod, 308015, Russia \\ E-mail: kuksova@bsu.edu.ru
}

\begin{abstract}
The French language is represented in many variants outside the metropolis, for example, in Switzerland. Despite the many unique features that distinguish the national specifics of the French language in Switzerland against the background of the general French norm, non-standard pronunciation to the greatest extent opposes the French language of the metropolis to the national version of the French language in Switzerland. The relevance of this research is determined by the fact that most of the works
\end{abstract}


devoted to the vocalism system of the national variant of the French language in Switzerland have lost their relevance and do not reflect the phonetic uniqueness of modern French-speaking Switzerland. The works of modern scholars abound in examples of cantonal pronunciation features, which are represented by isolated cases and do not reflect the general trends in the development of the vocalism system. In this regard, the author systematized data on the phonetic phenomena of the French language in Switzerland in the system of vocalism. The phonetic oppositions $[\tilde{\varepsilon}]-[\tilde{a}],[\alpha]-[\mathrm{a}],[0]-[0],[\mathrm{e}]-[\varepsilon],[\tilde{\varepsilon}]-[\tilde{e}]$ are studied. In the course of work with the factual material of the study, the author records the presence or absence of identified oppositions, and also clarifies the frequency of each case of opposition as a whole, regardless of the French-speaking canton.

Key words: francophony, national language variant, phonetics, vocalism, interference, national cultural specificity.

For citation: Kuksova E.L. 2020. The national french language variant's vocalism systemin switzerland: vowels'oppositions. Issues in Journalism, Education, Linguistics, 39 (3): 466-476 (in Russian). DOI 10.18413/2712-7451-2020-39-3-466-476

\section{Введение}

В современной лингвистике уделяется большое внимание проблемам функциональных и структурных характеристик территориальных разновидностей языка, на которых говорят национальные сообщества, географически отдаленные друг от друга. Такие разновидности языка получили название «национальный вариант». Данное понятие представляет собой совокупность «территориально ограниченных вариантов литературного языка, а также его социальных и территориальных диалектов и профессиональных языков» [Багана, 2004, с. 170].

Французский язык широко представлен за пределами метрополии национальными вариантами, на которых говорит и думает франкоязычное население франкофонных стран, таких как, например, Швейцария. Национальный вариант французского языка Швейцарии имеет свои регулярные отклонения от общефранцузской нормы на всех уровнях языка: фонетическом, лексико-семантическом, морфологическом и синтаксическом.

Несмотря на множество уникалий, выделяющих национальную специфику рассматриваемого варианта французского языка на фоне общефранцузской нормы, фонетические особенности в наибольшей степени противопоставляют французский язык метрополиинациональному варианту французского языка Швейцарии, нестандартное произношение которого сразу выдает носителя иной лингвокультуры.

Нередко особенности произношения, отличные от общеупотребимой нормы, связывают с историческими процессами, которые имели место на рассматриваемой территории, в том числе с историческим распределением языков и народов, проживающих в изучаемой языковой зоне [Чередниченко, 1983]. В то же время фонетические характеристики языка могут быть связаны с интерференцией иноязычных фонетических систем, поскольку представленный вариант языка зачастую является неродным для жителей той или иной территории. А.М. Молодкин пишет, что «фонологические черты языка, изучаемого в качестве второго, могут рассматриваться под углом интерференции со стороны родного языка, вследствие чего фонологическая система разновидности второго языка формируется в результате приспособления к ней существующей фонологической системы родного языка» [Молодкин, 2001, с. 144].

Интенсивность фонетических отклонений объясняется социолингвистическими факторами: во-первых, интерференцией, обусловленной соотношением и статусом контактирующих языков, а во-вторых, условиями общения и социальной принадлежностью говорящих. В Швейцарии количество отклонений и качество речи в большей степени за- 
висят от местной социально-бытовой и семейной речевой традиции, а также от уровеня образования самого говорящего.

О.А. Гулыга пишет о возможности проведения анализа специфического социоситуативного варьирования произношения у говорящего при наблюдениях над фонологией. Ученый подчеркивает, что «именно звучащая устная речь выдает социальный статус говорящего» [Гулыга, 2003, с. 170].

Однако не всегда местные фонетические специфические черты могут свидетельствовать о принадлежности к какой-либо социальной группе. Некоторые индивидуальные или даже групповые фонетические отклонения от общеупотребимой нормы выходят за пределы своего привычного использования и становятся общетерриториальными специфическими характеристиками, лишенными социальной окраски. В этом случае принято говорить о возникновении местного варианта литературного произношения.

Фонетическая специфика французского языка за пределами Франции обнаруживается в системе гласных (вокализме) и системе согласных (консонантизме) звуков. Нередко особенности произношения проявляются также и в просодических характеристиках речи, таких как ударение, ритм, мелодика. Наличие таких отличительных свойств речи свидетельствует о становлении собственного для рассматриваемой территории стиля литературного произношения, отличного от стиля общефранцузского варианта. Новый стиль произношения, как правило, признается нормативным и используется не только в разговорно-обиходной речи, но и в различных видах публичной речи.

Для описания фонетической специфики национального варианта французского языка Швейцарии рассмотрим характеристики центрально-французской нормы произношения.

Фонетическая система французского языка представлена группами гласных и согласных фонем, деление которых опирается на физиологические, акустические и фонематические критерии. Так, гласные звуки французского языка могут быть чистыми и носо-

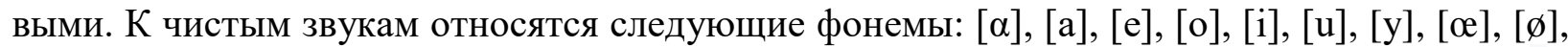

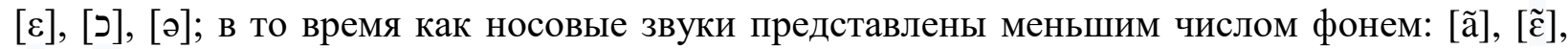

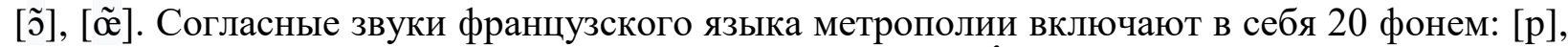
$[\mathrm{b}],[\mathrm{t}],[\mathrm{d}],[\mathrm{k}],[\mathrm{g}],[\mathrm{m}],[\mathrm{n}],[\mathrm{y}],[\mathrm{f}],[\mathrm{v}],[\mathrm{s}],[\mathrm{z}],[\mathrm{l}],[\mathrm{r}],[\mathrm{j}],[\mathrm{f}],[\mathrm{z}],[\mathrm{w}],[\mathrm{y}]$.

Ж. Багана пишет о количественном превосходстве французских гласных звуков в сравнении с другими языками, что, по мнению ученого, «является одной из причин неустойчивости французского вокализма, выхода из употребления некоторых звуков, стирания фонологических различий между существующими оппозициями. В отличие от системы гласных система согласных французского языка отличается относительной стабильностью» [Багана, 2004, с. 171].

Фонетическая система швейцарского варианта французского языка обладает специфическими характеристиками, отличными от общефранцузской нормы произношения. В настоящее время фонетические особенности швейцарского варианта французского языка малоизучены, а работы, посвященные фонетическим особенностям национального варианта французского языка, устарели и требуют актуализации, что увеличивает интерес к исследованию особенностей франко-швейцарского произношения.

Мнения зарубежных и отечественных лингвистов, занимающихся вопросами произношения во французском языке Швейцарии, не совпадают. Так, одни исследователи считают [Mertens, 1993; Thibault, 1998], что невозможно выделить единые фонетические особенности франкоговорящей части Швейцарии: швейцарский акцент французского языка отображается лишь в каждом отдельно взятом франкоговорящем кантоне, что, следовательно, сводит все исследования к изучению особенностей произношения только в рамках кантонов, а не страны в целом.

С другой стороны, существует мнение, что, несмотря на значительные фонетические расхождения между кантонами, возможно выделить общешвейцарские фонетические 
уникалии французского языка [Métral, 1977; Schoch, 1980]. Данные утверждения подкрепляются тем, что ряд особенностей произношения встречается в большинстве франкоговорящих кантонов страны, более того, данные фонетические характеристики имеют общие тенденции и закономерности развития. Сторонники данной точки зрения считают, что анализ специфики произношения отдельно взятых кантонов лишает исследователя возможности выявить системность фонетических явлений и их общие закономерности. Данное явление среди швейцарских и французских лингвистов получило название «accentsuisseroman» или «accentsuisseromandgénéral» [Métral, 1977, p. 150].

Изучение общих особенностей произношения французского языка в Швейцарии необходимо для детального изучения фонетической специфики отдельных регионов (кантонов, областей, муниципалитетов). В то же время знания о фонетическом строе речи отдельного кантона могут дополнить общее описание швейцарского варианта французского языка в целом.

Важную роль в формировании швейцарского акцента играют особенности системы вокализма. Изучению данного вопроса посвящены работы таких отечественных ученых, как Г.В. Гак [2019], О.А. Гулыга [2003], В.Т. Клоков [2009], Е.В. Ладыгина [2014], М.И. Олевская [2013]; а также зарубежных ученых - П. Мертенс [Mertens, 1993], Ж.-П. Метраль [Métral, 1977], М. Шох [Schoch, 1980] и других.

В системе вокализма швейцарского варианта французского языка имеет смысл рассматривать только отличные от общефранцузской нормы оппозиции гласных звуков. За основу данной работы взяты оппозиции, обнаруженные ранее зарубежными [Métral, 1977; Schoch, 1980; Mertens, 1993; Thibault, 1998] и отечественными [Дмитриева, 2008; Клоков, 2009; Ладыгина, 2014].

Большая часть работ, посвященных системе вокализма национального варианта французского языка Швейцарии, потеряла свою актуальность и не отображает фонетические уникалии современной франкоговорящей Швейцарии. С другой стороны, работы ученых изобилуют примерами кантональных особенностей произношения, которые представлены единичными случаями и не отображают общих тенденций развития системы вокализма. В связи с этим цель настоящего исследования состоит в доказательстве или опровержении существования представленных в работах лингвистов оппозиций гласных звуков, уточнении частотности каждого случая оппозиции в целом, вне зависимости от франкоговорящего кантона.

Практическим материалом исследования послужили видеоматериалы наиболее крупных швейцарских каналов RTS (Radio Télévision Suisse), Temps Présent и Miseau Point. В ходе работы с фактическим материалом исследования было отобрано свыше 700 примеров, которые, согласно цели исследования, свидетельствуют о наличии либо отсутствии выявленных оппозиций.

\section{Результаты и их обсуждения}

Для настоящего исследования были отобраны оппозиции, которые в работах лингвистов за 1980-2014 гг. отмечались как «отличительные» для швейцарского произноше-

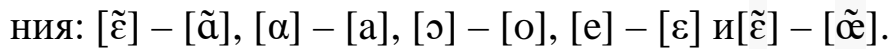

Оппозиция $[\tilde{\varepsilon}]-[\tilde{a}]$. Одна из наиболее примечательных особенностей швейцарско-

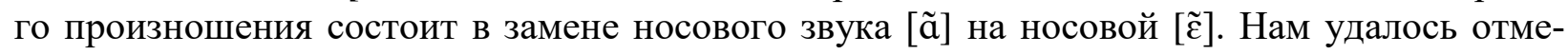

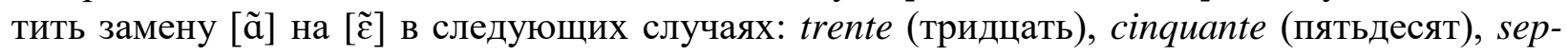
tante (семьдесят), nonante (девяносто), grand (большой), quand (когда), dans (в), а также в некоторых словах с суффиксами -ment, -mment.

Наличие данной оппозиции вызвано влиянием диалектных форм речи на фонетическую сторону речи франкоговорящих швейцарцев. Отметим, что в передачах крупных швейцарских каналов RTS (Radio Télévision Suisse), Temps Présent и Miseau Point эта особенность не ярко выражена: только 10,2 \% отобранных примеров звучали со звуком [च̃] 


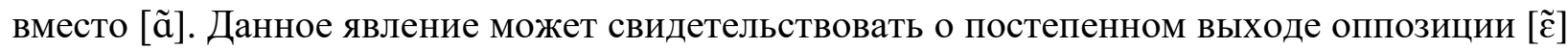
- [ã] из употребления.

Оппозиция [a] - [a]. В отличие от носителей французского языка, которые практически перестали использовать заднеязычный звук $[\alpha]$, заменив его на переднеязычный звук [a], франкоязычные швейцарцы употребляют заднеязычный $[\alpha]$ достаточно часто [Grosjean et al., 2007].

При работе с видеоматериалами каналов RTS (Radio Télévision Suisse), Temps

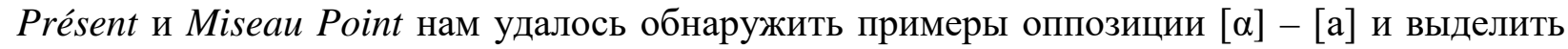
некоторые закономерности.

Так, рассматриваемая оппозиция наблюдается в частично омонимичных парах слов, таких как pâte [pat] (тесто) - patte [pat] (лапа), mâle [mal] (мужской) - mal [mal] (плохой), ras [в $]$ (гладкий) - rat [ва] (крыса). Важно отметить, что в представленных случаях оппозиция $[\alpha]-[a]$ играет смыслоразличительную роль.

Другой интересной закономерностью употребления звука $[\alpha]$ является его архаичное использование во всех словах с буквой «â» (помимо вышеупомянутых pâte, mâle и

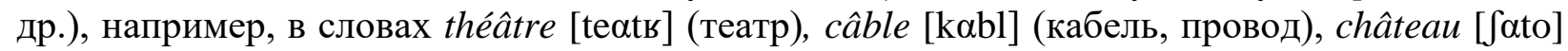
(замок), âge [az] (возраст) и др. Нам удалось идентифицировать 89,1 \% случаев использования звука $[\alpha]$ в слова с «â», в оставшихся $10,9 \%$ случаев звук $[\alpha]$ характеризовался меньшей напряженностью и глубиной, однако не переходил в гласный звук [а]. Можно сказать, что в $10,9 \%$ случаев речь шла о звуке $[\approx \alpha]$ или « $\alpha$-среднем».

В целом, употребление звука $[\alpha]$ в словах с «â» является архаизмом, который сохранился в национальном варианте французского языка Швейцарии: данная особенность была нормой общефранцузского происхождения, но вышла из употребления на территории Франции.

В ходе исследования нам удалось зафиксировать 34,8 \% случаев употребления звука $[\alpha]$ в словах, оканчивающихся на -as, например, pas [ра] (и как отрицательная частица, и в значении «шаг»), bas [ba] (низкий), là-bas [laba] (там). В 11 \% от общего числа примеров, также оканчивающихся на $-a s$, можно говорить об употреблении $[\approx \alpha]$ или « $\alpha-$ среднего», например, «matelas» [matl $\approx \alpha]$ (матрас).

Общий процент примеров, оканчивающихся на -as, где удалось выявить данное явление, не превышает 45,8 \%, поэтому можно говорить о существующей тенденции произношения слов, оканчивающихся на $-a s$, со звуком $[\alpha]$ или $[\approx \alpha]$. Данная тенденция, по нашему мнению, обусловлена в большей степени речевой привычкой говорящего.

В словах, содержащих буквосочетание -ass, также обнаруживается тенденция к произнесению звука $[\alpha]$ или $[\approx \alpha]$. В 27 \% случаев слова, содержащих буквосочетание -ass, произносятся с $[\alpha]$ или $[\approx \alpha]$, например, classe [klas] (класc), classique [klasik] (классический), (il)passe [(il)pas] ((он) проходит).

Данное явление отмечалось ранее в работах П. Мертенса [Mertens, 1993] и М. Шоха [Schoch, 1980] как индивидуальная особенность произношения отдельных языковых сообществ. В видеоматериалах каналов RTS (Radio Télévision Suisse), Temps Présent и Miseau Point нам все еще удается зафиксировать случаи употребления звука $[\alpha]$ или $[\approx \alpha]$ в словах с буквосочетанием -ass, что свидетельствует о существовании данной тенденции в настоящее время.

В работах А. Тибо [Thibault, 1998] и М. Шоха [Schoch, 1980] обращается внимание на возможность произнесения звука $[\alpha]$ или $[\approx \alpha]$ перед согласными звуками $[\mathrm{z}]$ и [3]. Нам удалось зафиксировать $38,2 \%$ случаев употребления звука [ $\alpha]$ перед согласными [z]

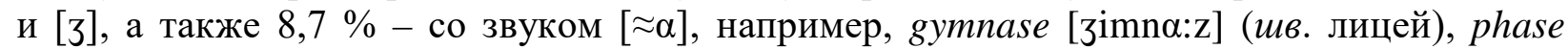

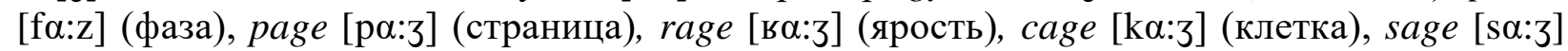
(прилежный)и др.

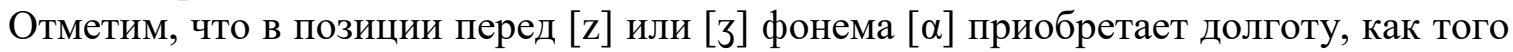
и требуют правила общефранцузского языка. Достаточно высокий процент обнаружения 
данного явления в современном национальном варианте французского языка Швейцарии свидетельствует о достаточно высокой частотности использования гласного звука $[\alpha]$ перед согласными звуками [z] и [3], т.е. речь идет об общешвейцарской тенденции употребления этого звука.

П. Мертенс [Mertens, 1993] и М. Шох пишут об использовании звука [ $\alpha$ в в словах с буквосочетанием «оi», отмечая, что использование звука $[\alpha]$ в данной позиции с $70-x$ годов XX века считается устаревшим. Однако Л.В Ладыгиной [2014] удалось зафиксировать данное явление в 2014 году в ходе полевых исследований особенностей французского языка Швейцарии.

Мы также обратили внимание на слова с буквосочетанием «оі» при работе с материалами каналов RTS (Radio Télévision Suisse), Temps Présent и Miseau Point. В ходе исследования было выявлено около $17 \%$ случаев употребления звукосочетания [wa] вместо

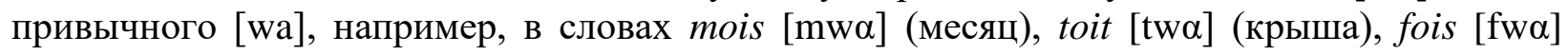

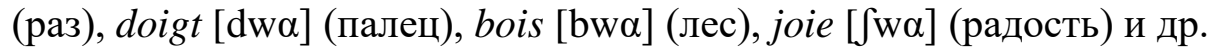

Мы смогли подтвердить случаи произношения звукосочетания [wa] только на конце слова. Данная тенденция обнаруживается редко, поэтому произношение слов с буквосочетанием «оi» со звуком $[\alpha]$ является индивидуальной или местной особенностью произношения, как индивидуальная или коллективная привычка, не достигающая общегосударственного или даже общекантонального уровня.

Говоря об использовании звука $[\alpha]$ в словах нефранцузского происхождения, отметим наличие данной фонемы в словах немецкого происхождения, таких как gautschage [got $\left.\int \alpha: 3\right]$ (традиция купания в фонтане или бассейне у учащихся полиграфических училищ по окончании обучения), neinsager [najnzag(ə)r] (лицо или общность, регулярно голосующие против во время народных референдумов), röstigraben [røftigrab(ә)n] (разрыв, взаимонепонимание, разница между франкоговорящими и немецкоговорящими швейцарцами). Данные лексические единицы были заимствованы франкошвейцарцами из немецкого язы-

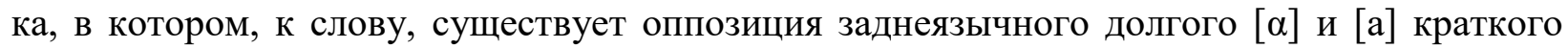
среднего ряда. В отличие от современного французского языка, в котором пропала смыс-

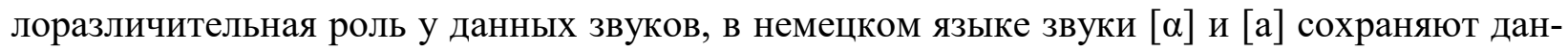
ную функцию, поэтому в заимствованных словах немецкого происхождения сохраняется звук, соответствующий смыслу высказывания [Ладыгина, 2014, с. 40].

К сожалению, в ходе работы с видеоматериалами каналов RTS (Radio Télévision Suisse), Temps Présent и Miseau Pointнам не удалось подтвердить или опровергнуть существование данного явления. Тем не менее, мы не исключаем возможность употребления звука $[\alpha]$ в словах нефранцузского происхождения. Частотность же употребления звука $[\alpha]$ в словах, заимствованных из немецкого языка, по нашему мнению, будет зависеть от частотности употребления этих лексических единиц.

Анализ приведённых примеров с оппозицией $[a]-[\alpha]$ показывает, что данная черта произношения в относительно равной степени характерна для всех франкоязычных носителей Швейцарии и достаточно часто встречается в речи франкоговорящих Швейцарцев (77,3\%), следовательно, данная фонетическая особенность является отличительной характеристикой швейцарского варианта французского языка.

Оппозиция [р] - [o]. Большинство зарубежных лингвистов (например, Métral, Knecht), описывая специфические особенности фонетической стороны речи франкошвейцарцев, отмечает употребление открытого переднеязычного гласного звука [э] на конце слов вместо закрытого заднеязычного [o]: например, abricot [abriko] вместо [abriko] (абрикос).

Однако, как пишет М. Матей [Matthey, 2003, p. 96], замена закрытого звука открытым не всегда осуществляется полностью. Ученый пишет о более открытом (по отношению к фонетической норме французского языка метрополии) произношении звука [o], который можно обозначить как [ح], указав тем самым близость новой фонемы, характерной для 
швейцарского варианта французского языка, к открытому звуку [о]. Матей называет получившийся звук «[о] тоуеп» или «[э] средний». Но даже в таких случаях этого бывает достаточно, чтобы различать ряд минимальных пар, например, разница в произношении крайне незначительна: pot (горшок) с открытым [э] и реаu (кожа) с закрытым [حっ]; sot (глупый) с [э]

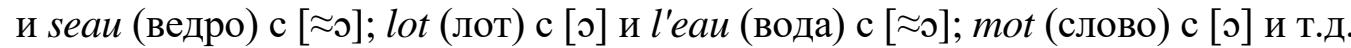

Ж.-П. Метраль [Métral, 1977] отмечает данное у носителей французского языка, живущих в кантоне Женева. При этом Метраль считает, что данное явление представляет собой архаизм, объясняя свое предположение тем, что раньше в произносительной норме французского языка Франции существовала оппозиция фонетически конечного «о», который мог быть как отрытым, так и закрытым.

П. Мертен [Mertens, 1993, p. 41] обращает внимание на обратную тенденцию употребления более закрытого звука [о] вместо переднеязычного звука [о]. Данное явление исследователь обнаруживает в кантонах Юра, Вале и Невшатель, при этом ученый отмечает, что позиция звука в слове не играет важной роли: носители данной фонетической особенности придерживаются звука $[\approx 0]$ усредненного вместо открытого и закрытого звуков, что создает впечатление, будто носители заменяют переднеязычный открытый [э] в словах. Ученый приводит пример употребления усредненного звука [حо] в словах proche (близкий), poste (почта), effort (усилие), mort (смерть) и др.

Отметим, что усредненные звуки [حо] и $[\approx 0]$ являются качественно разными фонемами, каждая из которых приближена в большей степени к своему обычному эквиваленту.

Итак, помимо архаичного употребления фонетически конечных заднеязычных [о], ранее свойственных и французскому языку Франции, в современной Швейцарии наблюдаются тенденции употребления усредненных фонем [ح0], в большей степени открытой, и $[\approx 0]$, в большей степени закрытой. Тенденция произносить усредненные фонемы [حо] и $[\approx 0]$ обнаружила себя в $46,3 \%$ случаев.

Несмотря на то, что письменные источники соотносят оппозицию [о] - [o] с отдельными кантонами, в отобранных нами примерах данное явление удалось зафиксировать в 54 \% случаев. При этом носители чаще отдавали предпочтение усредненным фонемам $[\approx 0]$ и $[\approx 0](46,3 \%$ случаев). Важно отметить, что в одном контексте слова с рассматриваемой оппозицией могли звучать по-разному у одного и того же говорящего (9\%):

«La fatigue cronique, c'est de vouloir quand on n'a pas d'exemen clairement niveau [₹o] diagnostique tant dans la population mais aussi au niveau [₹o] du corps médical de dire on n'a rien mesuré» [RTS, Quand la fatigue devient chronique (youtube)]. - Хроническая усталость - это заболевание, которое еще четко не диагностировали у населения и которое также не имеет теоретической базы в медицине, как если бы его не было совсем.

В данном примере говорящий (prof. Pierre-YvesRo) произносит слово «niveau»

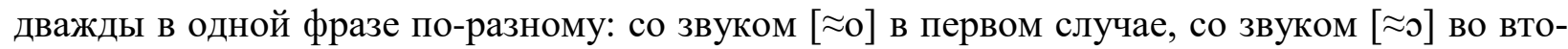
ром. Согласно общефранцузской нормы слово niveau звучит с конечным заднеязычным [о]. Однако говорящий «смягчает» звучание грубого глубокого гласного звука, усредняя его до $[\approx 0]$ и $[\approx 0]$. Оба случая отличаются от фонемы [o], которая должна была прозвучать в соответствии с правилами общефранцузского языка, а также отличаются друг от друга у одного носителя в одной фразе. При этом говорящий обладает слабой артикуляцией и практически не округляет губы при произнесении слова niveau.

Вероятно, возникновение оппозиции [0] - [о] вызвано влиянием местных диалектов на французский язык, а также варьирует в зависимости от индивидуальных особенностей говорящего (его желания и привычки в большей степени; уровня образования и социального положения - в меньшей). Данное явление можно считать высокочастотным, общегосударственным. Однако есть вероятность, что в скором времени тенденция произносить усредненные фонемы $[\approx 0]$ и [حо] вытеснит оппозицию[о] - [o], что приведет к ее постепенному стиранию. 
Оппозиция [е] - [ع]. Работы, описывающие особенности произношения швейцар-

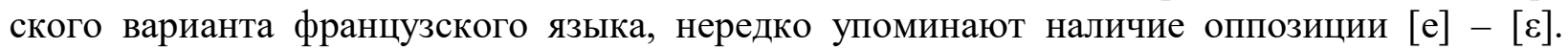
Данная оппозиция является наиболее противоречивой. С одной стороны, как и в ранее описанных случаях, Ж.-П. Метраль [Métral, 1977, pp. 155] отмечает наличие и частотное употребление (не только в разговорном стиле) так называемого е тоуеn или «е» среднего. С другой стороны, ученый пишет о предпочтительном использовании открытого звука [ع] вместо закрытого [е], если последний находится в безударном положении. Как правило, данное явление наблюдается в словах, где «е́» стоит в безударном положении, например, étudiant, étoile, préparer и др. Лингвист также приводит в пример различное произношение слов d'étoiles [detwal] (звезд, сущ., род.п.) - destoiles (паруса, сущ, мн.ч.) [detwal]. Оппозиция $[\varepsilon]-[\mathrm{e}]$ рассматривается также как архаизм чтения окончаний глаголов, оканчивающихся на -ais / -ai, например, jeviendrais (я пришел бы) с открытым $[\varepsilon]$ на конце и jeviendrai (я приду) с закрытым [е] на конце.

Интересно отметить, что данное явление имеет обратную тенденцию. А. Тибо [Thibault, 1998] упоминает, что франкоговорящие жители кантонов Юра и Вале (особенно Юра) чаще употребляют закрытый звук [е] вместо открытого [в]. Например, anglais (английский), scolaire (школьный), lemaire (мэр), mère (мама), jemettrais (я положил бы). Это явление также кратко упоминается П.П. Кнештом [Knecht, 1979], который, в свою очередь, приписывал данное явление жителям кантонов Невшатель и Вале. Несмотря на то, что предпочтительное использование $e$ mоуеп или $[\varepsilon]$ в основном свойственно жителям Швейцарии, в последние годы сами французы констатируют случаи употребления среднего «е» на территории Франции. Однако, по мнению М.И. Олевской [Олевская 2013, с. 56], во Франции употребление $[\varepsilon]$ вместо [e] - пока лишь тенденция, а не норма.

В отобранных нами примерах из передач канала Temps Présent данное явление встречается относительно часто: 30,8 \% случаев свидетельствуют о наличии оппозиции [е]

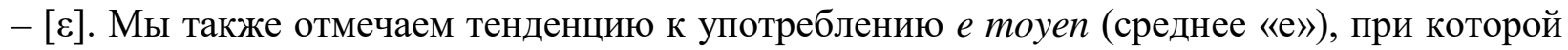
происходит стирание оппозиции $[\mathrm{e}]=[\varepsilon]$, например, perser $=$ persais $($ прорывать $=$ рвал), regardez $=$ regardais (посмотрите $=$ смотрел) и др. (примеры из репортажа Temps Présent: "Les verts vont-ils renverser la coupole?") Данное явление особенно ярко выражено в глагольных формах, где полностью отсутствует конечный звук [е].

В целом, в национальном варианте французского языка Швейцарии можно говорить об устаревании оппозиции $[\mathrm{e}]-[\varepsilon]$ и ее стирании. Данное явление вызвано развитием собственной разговорной традиции и не связано с интерференцией соседствующих языков (например, немецкий) или диалектов.

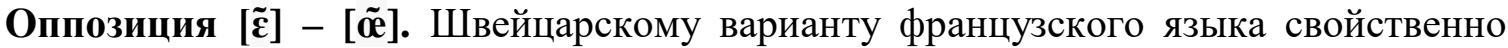

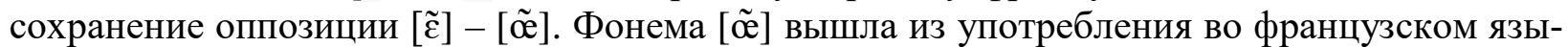

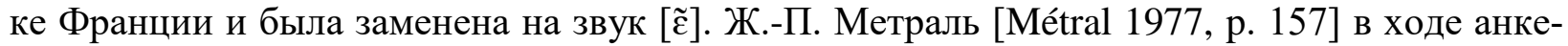

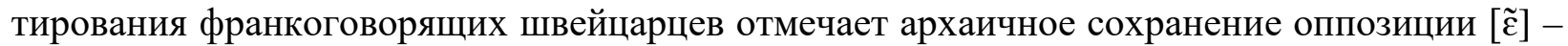

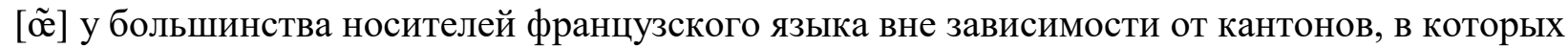
проводилось исследование.

К сожалению, в серии репортажей каналов Temps Présent и RTS нам не удалось отметить данное явление. Дикторы передач и простые граждане, выступающие на канале, придерживаются современной общефранцузской тенденции $[\tilde{\varepsilon}]=[\tilde{\tilde{e}}]$, например, un $[\tilde{\varepsilon}]$ vraicadeau (настоящий подарок), aucun [حokẽ] proplème (никакой проблемы) и др. (примеры из репортажа Temps Présent: "Voitures, à quand la fin de l'enfumage").

Мы полагаем, что оппозиция $[\tilde{\varepsilon}]-[\tilde{\alpha}]$ вышла из употребления в городах. Однако мы не исключаем возможность присутствия оппозиции в сельской местности, где влияние диалектных форм речи выше, а уровень образования ниже. 


\section{Выводы}

Характерные, национально-культурные и социолингвистические характеристики вариантов французского языка в мире определяются специфическими чертами, выявленными в этих вариантах на всех языковых уровнях: фонетическом, лексико-семантическом, морфологическом и синтаксическом.

В разговорной речи важное место занимают фонетические особенности языка. Чтобы выявить и проанализировать характерные для швейцарского варианта французского языка фонетические особенности мы рассмотрели языковую норму произношения французского языка Франции и действующие в швейцарском варианте французского языка отклонения от общефранцузской нормы. Выявленные отклонения от нормы могут быть объяснены интерференцией диалектных форм речи и диглоссией, архаизацией швейцарского варианта французского языка, а также индивидуальными предпочтениями (привычками) говорящего или группы говорящих.

В ходе исследования фонетических особенностей в системе вокализма французского языка Швейцарии были выявлены отклонения в следующих оппозициях: $[\tilde{\varepsilon}]-[\tilde{a}],[\alpha]-$

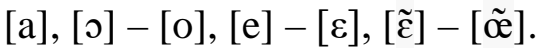

Среди обнаруженных явлений наиболее распространенными являются оппозиции $[\tilde{\varepsilon}]-[\tilde{a}],[\alpha]-[a]$ и[о] - [o]. Оппозиция $[\mathrm{e}]-[\varepsilon]$ все еще встречается в национальном варианте французского языка Швейцарии, но в наших примерах отмечается процесс стирания оппозиции $[\mathrm{e}]=[\varepsilon]$. Данное явление частично затрагивает и оппозицию $[\circ]-[o]$, ко-

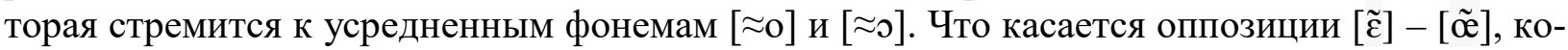
торая еще в 2000-х гг. считалась отличительным признаком франкошвейцарского произношения, то сейчас (в 2019-2020 гг.) данное явление с трудом обнаруживается в устной речи (передачи каналов RTS (Radio Télévision Suisse), Temps Présent и Miseau Point).

Отметим, что фонетические особенности во многом являются не только отражением национальной и (или) социальной специфики речи, зависящей от возраста, пола, уровня образования, места жительства, рода деятельности и т.д. говорящего, но и являются индивидуальной особенностью каждого человека (его привычки и поведение, особенности артикуляции, некоторые анатомические особенности, например, прикус и др.)

\section{Источники}

Гак В.Г., Мурадова Л.А. 2019. Введение во французскую филологию. Москва, Юрайт, 303 с.

\section{Список литературы}

1. Багана Ж. 2004. Языковая интерференция в условиях франко-конголезского билингвизма. Дис. ... докт. филол. наук. Белгород, 353 с.

2. Гулыга О.А. 2003. Дидактический акцент как проявление социоситуативного варьирования. В кн. IV Степановские чтения. Функционирование языковых единиц в аспекте национально-культурной специфики. Тезисы докладов и сообщений Международной конференции, г. Москва, 15-16 апреля 2003 года. Москва, Изд-во РУДН: 170-171.

3. Дмитриева Е.Г. 2008. Лексико-семантические и стилистические особенности французского языка в Швейцарии: дис. ... канд. филол. наук: 10.02.05. М., 227 с.

4. Клоков В.Т. 2009. Французский язык в Швейцарии. Саратов, Изд-во Сарат. ун-та, 214 с.

5. Ладыгина Е.В. 2014. Французский язык в Швейцарии. Дис. ... канд. филол. наук. Москва, 186 с.

6. Молодкин А.М. 2001. Взаимодействие языков разного типа в этнокультурном контексте. Саратов, Изд-во Саратов. ун-та, 184 с.

7. Олевская М.И. 2013. Фонетика французского языка. Практический курс. Cours pratique de la phonétique française. М., Нестор Академик, 192 c.

8. Чередниченко А.И. 1983. Язык и общество в развивающихся странах Африки. Киев, Изд-во при Киев. ун-те, 165 с. 
9. Durand J., Laks B., Lyche C. 2003. La prononciation du français dans sa variation La Tribune Internationale des Langue Vivantes, Vol. 33: 3-9.

10. Grosjean F., Carrard S., Godio C., Grosjean L., Dommergues J. Long and short vowels in Swiss French: their production and perception. French language studies, Vol. 17: 1-19.

11. Knecht P. 1979. Le français en Suisse romande: aspects linguistiques et sociolinguistiques. Le français hors de France. Ed. A. Valdman. Paris, Honoré Champion: 249-258.

12. Matthey M. 2003. Le français langue de contact en Suisse romande. Glottopol, 2: 92-100.

26: $26-69$.

13. Mertens P. 1993. Accentuation, intonation et morphosyntaxe. Travaux de linguistique, Vol.

14. Métral P. 1977. Le vocalisme du français en Suisse romande: considérations phonologiques. Cahiers Ferdinand de Saussure, Vol. 31: 147-176. 133-136.

15. Pohl J. 1986. Une parenté phonologique belgo-suisse archaïsante. La linguistique, 22 (2):

16. Racine I., Andreassen H. 2012. A phonological study of a Swiss French variety. Phonological variation in French: Illustrations from three continents Eds. Randall Gess, Chantal Lyche and Trudel Meisenburg. Amsterdam, John Benjamins: 173-207.

17. Schoch M. 1980. Résultats d'une enquête phonologique en Suisse romande. Bulletin de la Section de linguistique de la Faculté des lettres de Lausanne, 2: 1-38.

18. Singy P. 1996. Les francophones de périphérie face à leur langue: étude de cas en Suisse romande. Cahiers Ferdinand de Saussure, Vol. 49: 213-235.

19. Thibault A. 1998Légitimité linguistique des français nationaux hors de France: le cas du français de Suisse romande. Revue québécoise de linguistique, 26 (2): 25-42.

\section{References}

1. Bagana Zh. 2004. Yazykovaya interferentsiya v usloviyakh franko-kongolezskogo bilingvizma [Linguistic interference in conditions of the Franco-Congolese of bilingualism]. Dis. ... doct. philol. sciences'. Belgorod, 353 p.

2. Gulyga O.A. 2003. Didakticheskiy aktsent kak proyavlenie sotsiosituativnogo var'irovaniya [Didactic emphasis as a manifestation of socioemotional of variation]. In: IV Stepanovskie chteniya. Funktsionirovanie yazykovykh edinits $\mathrm{v}$ aspekte natsional'no-kul'turnoy spetsifiki [IV Stepanovsky readings. Functioning of language units in the aspect of national and cultural specificity]. Abstracts of reports and reports of the International conference, Moscow, April 15-16, 2003. Moskva, Publ. Izd-vo RUDN: $170-171$.

3. Dmitriyeva Ye.G. 2008. Leksiko-semanticheskiye i stilisticheskiye osobennosti frantsuzskogo yazyka v Shveytsarii [Lexico-semantic and stylistic features of the French language in Switzerland], thesis... Cand. Philol. Sciences: 10.02.05. Moscow, 227 p.

4. Klokov V.T. 2009. Frantsuzskiy yazyk v Shveytsarii. [French in Switzerland]. Saratov, Publ. Izd-vo Sarat. un-ta, $214 \mathrm{p}$.

5. Ladygina E.V. 2014. Frantsuzskiy yazyk v Shveytsarii [French in Switzerland]. Dis. ... cand. philol. sciences'. Moscow, 186 p.

6. Molodkin A.M. 2001. Vzaimodeystvie yazykov raznogo tipa v etnokul'turnom kontekste [Interaction of different types of languages in an ethno-cultural context]. Saratov, Publ. Izd-vo Saratov. un-ta, $184 \mathrm{p}$.

7. Olevskaya M.I. 2013. Fonetika frantsuzskogo yazyka. Prakticheskiy kurs. Cours pratique de la phonétique française [Phonetics of the French language. Practical course. Cours pratique de la phonétique française]. M., Publ. Nestor Akademik, 192 p.

8. Cherednichenko A.I. 1983. Yazyk i obshchestvo v razvivayushchikhsya stranakh Afriki [Language and society in developing countries in Africa]. Kiev, Publ. Izd-vo pri Kiev. un-te, 165 p.

9. Durand J., Laks B., Lyche C. 2003. La prononciation du français dans sa variation La Tribune Internationale des Langue Vivantes, Vol. 33: 3-9.

10. Grosjean F., Carrard S., Godio C., Grosjean L., Dommergues J. Long and short vowels in Swiss French: their production and perception. French language studies, Vol. 17: 1-19.

11. Knecht P. 1979. Le français en Suisse romande: aspects linguistiques et sociolinguistiques. Le français hors de France. Ed. A. Valdman. Paris, Honoré Champion: 249-258.

12. Matthey M. 2003. Le français langue de contact en Suisse romande. Glottopol, 2: 92-100. 
13. Mertens P. 1993. Accentuation, intonation et morphosyntaxe. Travaux de linguistique. Vol. 26: 26-69.

14. Métral P. 1977. Le vocalisme du français en Suisse romande: considérations phonologiques. Cahiers Ferdinand de Saussure, Vol. 31: 147-176. 133-136.

15. Pohl J. 1986. Une parenté phonologique belgo-suisse archaïsante. La linguistique, 22 (2):

16. Racine I., Andreassen H. 2012. A phonological study of a Swiss French variety. Phonological variation in French: Illustrations from three continents Eds. Randall Gess, Chantal Lyche and Trudel Meisenburg. Amsterdam, John Benjamins: 173-207.

17. Schoch M. 1980. Résultats d'une enquête phonologique en Suisse romande. Bulletin de la Section de linguistique de la Faculté des lettres de Lausanne, 2: 1-38.

18. Singy P. 1996. Les francophones de périphérie face à leur langue: étude de cas en Suisse romande. Cahiers Ferdinand de Saussure, Vol. 49: 213-235.

19. Thibault A. 1998Légitimité linguistique des français nationaux hors de France: le cas du français de Suisse romande. Revue québécoise de linguistique, 26 (2): 25-42.

\section{ИНФОРМАЦИЯ ОБ АВТОРЕ}

Куксова Елена Леонидовна, доцент кафедры второго иностранного языка института межкультурной коммуникации и международных отношений Белгородского национального исследовательского университета, г. Белгород, Россия

\section{INFORMATION ABOUT THE AUTHOR}

Elena L. Kuksova, associate Professor of the second foreign language Department, Institute of intercultural communication and international relations, Belgorod national research University, Belgorod, Russia 